\title{
Epidemiology of laboratory-confirmed mumps infections in South Africa, 2012- 2017: a cross-sectional study
}

\author{
Mpho Lerato Sikhosana ${ }^{*^{*}}$ D, Lazarus Kuonza ${ }^{1,2,3}$ and Nkengafac Villyen Motaze,
}

\begin{abstract}
Background: Data on the burden of mumps in South Africa are limited and the epidemiology of mumps in this setting is not well understood. We present an analysis of mumps data in South Africa from 2012 to 2017.

Methods: This cross-sectional study included secondary data on laboratory-confirmed mumps infections from 2012 to 2017, archived at the South African National Health Laboratory Services' data repository as well as from four private laboratories. Mumps-specific immunoglobulin M (IgM) and/or viral nucleic acid positive results represented acute infections. We used age-specific mid-year population estimates for each study year as denominators when calculating annual cumulative incidence. Seasonality was based on the season that showed a peak in infections.

Results: Out of 48,580 records obtained from the public and private sectors, 46,713 (96.2\%) were from the private sector. Over the study period, there were 7494 acute infections, 7085 (94.5\%) of which were recorded in the private sector. Of these 7494 infections, 3924 (52.4\%) occurred in males. The proportion of samples tested that were $\lg M$ positive was $18.6 \%(1058 / 5682)$ in $2012,15 \%(1016 / 6790)$ in $2013,15.8 \%(1280 / 8093)$ in $2014,15.5 \%(1384 / 8944)$ in 2015, 13.1\% (1260/9629) in 2016 and 15.8\% (1496/9442) in 2017. The cumulative incidence rate per 100,000 was highest in children between one and 9 years throughout the study period. The cumulative incidence of infections was highest in the Western Cape, Gauteng and the Northern Cape. Infections peaked in June and November.

Conclusion: Laboratory-confirmed mumps infections predominantly occurred in spring, affecting children below 10 years of age and individuals who were male. There were fewer tests performed in the public sector compared to the private sector. Since only laboratory data was analysed our results represent and underestimate of disease burden. Further studies that include clinical data are required to provide better estimates of disease burden in South Africa.
\end{abstract}

Keywords: Mumps, Epidemiology, Public health sector, Private health sector, Acute infections, Immunity

\section{Background}

Mumps is usually a childhood illness that mostly affects children aged 5-9 years although adolescents and adults can be infected [1]. In the absence of a mumps-containing vaccine $(\mathrm{MuCV})$, the annual incidence of mumps was

\footnotetext{
* Correspondence: Isikhosana@gmail.com

'South African Field Epidemiology Training Programme, National Institute for Communicable Diseases, Division of the National Health Laboratory Service, Johannesburg, South Africa

Full list of author information is available at the end of the article
}

estimated to be between 100 and 1000 cases/100000 population [1]. By the end of 2018, 122 countries worldwide had introduced the vaccine in their respective national immunization programmes, with the annual reported number of cases being 499,512 worldwide [2, 3]. However, there has been reports of mumps outbreaks in previously adequately vaccinated populations recently, indicating possible waning immunity [4-10].

(c) The Author(s). 2020 Open Access This article is licensed under a Creative Commons Attribution 4.0 International License, which permits use, sharing, adaptation, distribution and reproduction in any medium or format, as long as you give appropriate credit to the original author(s) and the source, provide a link to the Creative Commons licence, and indicate if changes were made. The images or other third party material in this article are included in the article's Creative Commons licence, unless indicated otherwise in a credit line to the material. If material is not included in the article's Creative Commons licence and your intended use is not permitted by statutory regulation or exceeds the permitted use, you will need to obtain permission directly from the copyright holder. To view a copy of this licence, visit http://creativecommons.org/licenses/by/4.0/. The Creative Commons Public Domain Dedication waiver (http://creativecommons.org/publicdomain/zero/1.0/) applies to the data made available in this article, unless otherwise stated in a credit line to the data. 
Mumps is not a notifiable disease in South Africa [11]. This contributes to the sparse epidemiological data about the disease and the baseline incidence of mumps infections not being known. Between 1999 and 2018, only two Southern African countries (Eswatini and Zambia) frequently reported mumps cases, while South Africa only reported 24 cases in 2002 [12].

Important policy and programmatic considerations regarding the introduction of a MuCV into a country's immunization programme include the burden of mumps disease, the efficiency of the country's national immunization programme, the socioeconomic impact of the vaccine introduction, and the ability of the country to achieve and maintain a coverage $>80 \%$ for the measlesand rubella-containing vaccines [13]. A vaccine coverage $>80 \%$ for the measles- and rubella-containing vaccines demonstrates a country's ability to achieve a similar or higher coverage for the MuCV. A suboptimal coverage would result in an epidemiological shift of disease, leading to a higher incidence of mumps infections in the older age-groups. An increase in age has been associated with more severe disease in many childhood diseases, and in mumps infections, this increased risk occurs more commonly in males compared to females [10,14] The World Health Organization (WHO) also recommends that should a MuCV be introduced by a country, it should be as two doses given at 12-18 months then from 2 up to 6 years in the form of the trivalent measles-mumps-rubella (MMR) vaccine. Mumps should also be included in the country's list of notifiable diseases that would be under surveillance. By 2017, only four countries in the African region (Seychelles, Mauritius, Cabo Verde and Algeria) had introduced the MuCV in their respective national vaccination program, while in South Africa, MuCV was only available in the private health sector as MMR and was not part of the Extended Programme of Immunizations (EPI) that provides vaccines to children in the public health sector [15-17].

We therefore aimed to describe the epidemiology of laboratory-confirmed mumps infections in South Africa between January 2012 to December 2017, with the objectives of estimating the cumulative incidence of laboratory-confirmed infections as well as determining whether the infections had periodic fluctuations.

\section{Methods}

\section{Study design and setting}

This was a cross-sectional study using laboratory data from both private and public health sectors, from January 2012 to December 2017. The study period was chosen because mumps data was recorded more consistent in both health sectors during this period. Public sector data were obtained from the data repository of the National Health Laboratory Service (NHLS). The NHLS is the largest diagnostic pathology service provider in South Africa and provides laboratory services to $\geq 80 \%$ of the population through a network of over 260 laboratories throughout the country [18]. Private sector data were obtained from four private laboratories (Ampath, Lancet, PathCare and Vermaak \& Partners). Data included patient's demographic information as well as test results.

\section{Operational definitions}

Positive mumps-specific immunoglobulin $M(\operatorname{IgM})$ and/ or viral nucleic acid (NA) results represented acute infections. Results positive only for mumps-specific immunoglobulin $G$ (IgG) represented previous exposure to mumps. Age-specific cumulative incidence rates were calculated using the number of acute infections per year as the numerator and the age-specific mid-year population estimates as denominators [19-24]. Mid-year population estimates for 2012 were not available, therefore the average of estimates for 2011 and 2013 were used to calculate the 2012 age-specific estimates. A seasonal pattern was determined by the months that showed a peak in the number of infections.

\section{Participants, sample size and sampling}

All samples tested for mumps at the NHLS and the four private laboratories during the study period were included.

\section{Data management and analysis}

Stata statistical software version 15 (StataCorp. 2017. Stata Statistical Software: Release 15. College Station, TX: StataCorp LLC) was used for data cleaning and analysis.

\section{Ethical considerations}

Ethics approval for conducting this study was obtained from the Faculty of Health Sciences Research Ethics Committee of the University of Pretoria (ref. 539/2017). Institutional clearance was also obtained from the NHLS Academic Affairs, Research and Quality Assurance as well as the relevant ethics committees of the respective private laboratories.

\section{Results}

A total of 48,580 records were used in the analysis. Participant characteristics are summarized in Table 1 . Of these records, 46,713 (96.2\%) were from the private sector. There were $186(0.4 \%)$ records with missing information on age, $143(0.3 \%)$ on gender, $15,993(32.9 \%)$ on sample type and $15,175(31.2 \%)$ on province. There were 26,640 (54.8\%) records from samples collected from females. There were 10,279 samples from children $\leq 9$ years, of which 9583 (93.2\%) were from the private sector. Types of specimens submitted to both health sectors 
Table 1 Characteristics of samples submitted for mumps testing in public and private sectors, 2012-2017, $(n=48,580)$

\begin{tabular}{|c|c|c|c|}
\hline Variable & Public Sector, n (\%) & Private Sector, n (\%) & Total n (\%) \\
\hline \multicolumn{4}{|l|}{ Gender } \\
\hline Female & $1046[4]$ & $25,594(96)$ & $26,640(100)$ \\
\hline Male & $788(4)$ & $21,009(96)$ & $21,797(100)$ \\
\hline \multicolumn{4}{|l|}{ Age } \\
\hline$<1$ & $139(9)$ & $1423(91)$ & $1562(100)$ \\
\hline $1-4$ & $317(7)$ & $4080(93)$ & $4397(100)$ \\
\hline $5-9$ & $240(6)$ & 4080 (94) & $4320(100)$ \\
\hline $10-19$ & $263(4)$ & $6061(96)$ & $6324(100)$ \\
\hline $20-29$ & $299(4)$ & $7184(96)$ & $7483(100)$ \\
\hline $30-39$ & $214(2)$ & $9866(98)$ & $10,080(100)$ \\
\hline$>40$ & $227(2)$ & $14,001(98)$ & $14,228(100)$ \\
\hline Unknown & $168(90)$ & $18(10)$ & $186(100)$ \\
\hline \multicolumn{4}{|l|}{ Province } \\
\hline EC & $71(21)$ & $272(79)$ & $343(100)$ \\
\hline FS & $63(18)$ & $286(82)$ & $349(100)$ \\
\hline GP & $933(6)$ & $16,026(94)$ & $16,959(100)$ \\
\hline KZN & $193(2)$ & $8116(98)$ & $8309(100)$ \\
\hline LP & $51(6)$ & $822(94)$ & $873(100)$ \\
\hline MP & $114(8)$ & $1245(92)$ & $1359(100)$ \\
\hline NW & $67(9)$ & $663(91)$ & $730(100)$ \\
\hline NC & $60(17)$ & $285(83)$ & $345(100)$ \\
\hline WC & $315(8)$ & $3823(92)$ & $4138(100)$ \\
\hline
\end{tabular}

EC Eastern Cape; FS Free State; GP Gauteng; KZN KwaZulu Natal; LP Limpopo; MP Mpumalanga; NW North West; NC Northern Cape; WC Western Cape

over the study period are shown in Fig. 1. There were 20,279 (41.7\%) cerebrospinal fluid samples, and 12,144 (25.0\%) blood samples (this includes samples labelled "blood" and "blood culture") (Fig. 1). The highest number of samples submitted overall was from Gauteng Province 16,959 (50.8\%), while the lowest number of samples was from the Eastern Cape, Northern Cape and
Free State Provinces (343 (1\%), 345 (1\%) and 349 (1\%) respectively).

Overall, there were 7494 infections recorded during the study period, 7085 (94.5\%) of which were in the private sector (Fig. 2). Most of these infections were recorded in 2017 (1496/7494; 20\%), while the least number of infections occurred in 2013 (1016/7494; 13.6\%). Most (3061/3198; 95.7\%) of the infections were diagnosed from blood samples. Except for 2013, there was consistently more infections amongst males (Table 2). The highest absolute numbers of acute infections were recorded in the Gauteng (1601), Western Cape (965) and KwaZulu Natal (626) provinces overall (Fig. 2), however the highest cumulative incidence per 100,000 of infections occurred in Western Cape, Gauteng and Northern Cape, in that order (Fig. 3). On average, the cumulative incidence was highest in $2017(1,43$ cases/100000 population) and lowest in 2013 (0,60 cases/100000 population). The cumulative incidence was high amongst children in the 1-4 and 5-9year age groups (Fig. 4). When the cumulative incidences of mumps infections in these two most affected age-groups were plotted according to geographic distribution, the highest incidence was in the Western Cape (Figs. 5 and 6). When the absolute numbers of infections were plotted by month, two peaks were observed in June and November throughout the study period (Fig. 7). The province with the highest proportion of cases with evidence of previous exposure to mumps exposure throughout the study period was Gauteng (Table 3).

\section{Discussion}

In this paper, we report the number of tests positive for mumps in South Africa between 2012 to 2017. Most of these cases were reported by the private sector laboratories and occurred mostly in the 1-4 and 5-9 age groups. This age distribution is consistent with what has been reported in other countries during the pre-MuCV

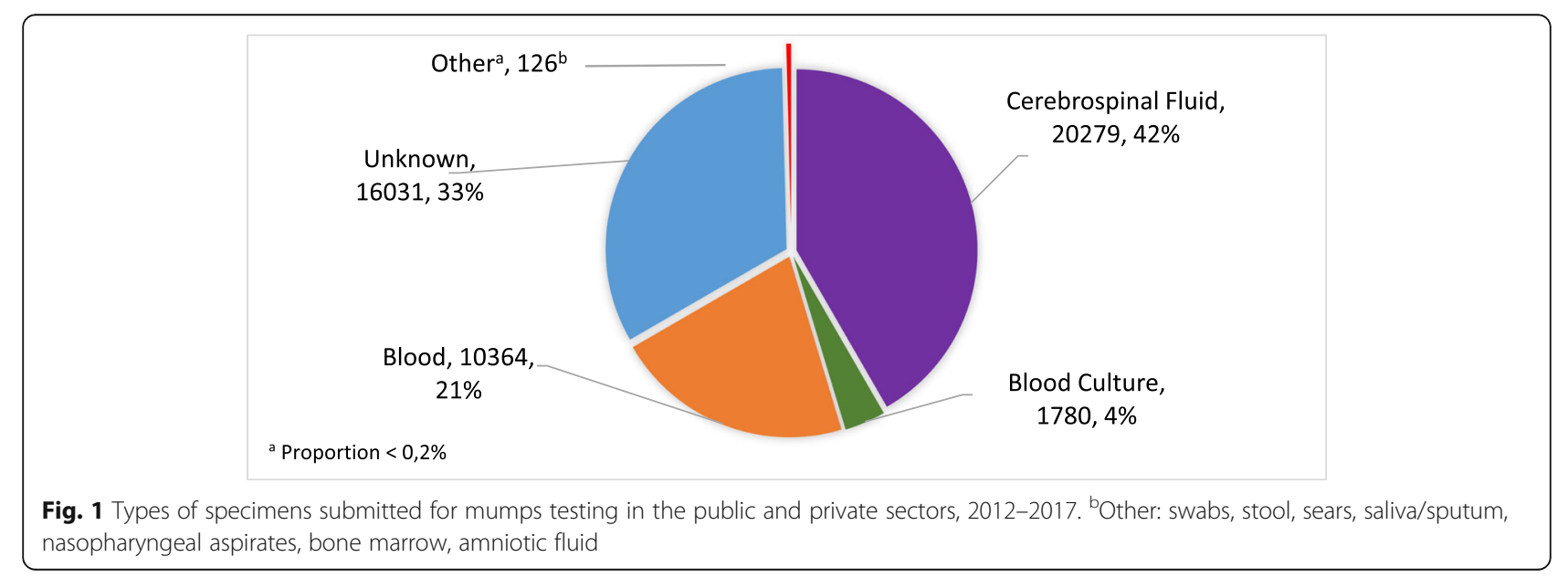




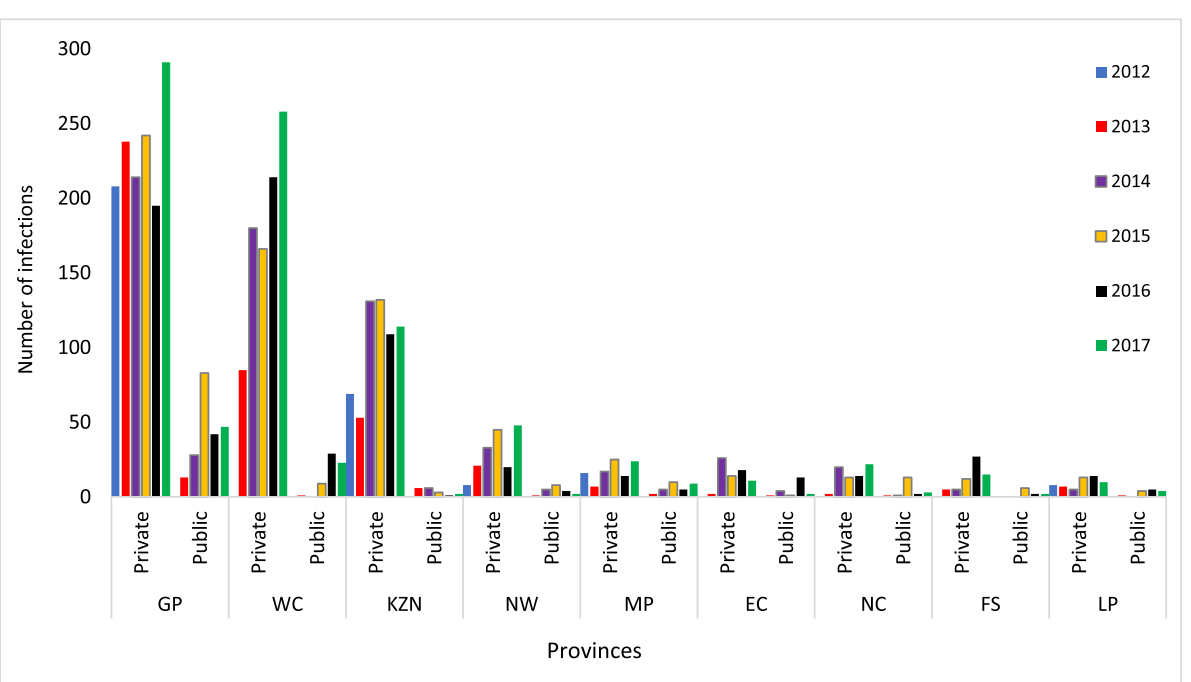

Fig. 2 Absolute number of laboratory-confirmed acute mumps infections recorded in the public and private sectors by province, 2012-2017

era, with most of the infections reported in children below 10 years of age [1]. The cumulative incidence of mumps in our setting was found to be lower than that reported in Western countries during the pre-vaccine era. This most likely reflects under-reporting of mumps since the disease is neither notifiable nor under surveillance. The low incidence could also mean that the reported cases represent patients with more severe presentation of the disease, such as mumps-associated meningitis or orchitis, in whom further investigations would have been conducted. The results could also indicate diagnostic practises in our setting, with mumps possibly only being diagnosed clinically if a patient presented with a typical presentation of parotid enlargement. This would suggest that mumps cases presenting with other complications of the disease could have possibly been undiagnosed and therefore not be accounted for in the analysed results. Also, had there been an outbreak of mumps during the study period, this may have been unidentified.

Table 2 Absolute number and percentages of infections reported in public and private sectors by gender, 2012-2017

\begin{tabular}{llll}
\hline Sex & Female $\mathrm{n}(\%)$ & Male $\mathrm{n}(\%)$ & Total $\mathrm{n}(\%)$ \\
\hline $\mathbf{2 0 1 2}$ & $497(47,02)$ & $560(52,98)$ & $\mathbf{1 0 5 7}(\mathbf{1 0 0})$ \\
$\mathbf{2 0 1 3}$ & $517(51,14)$ & $494(48,86)$ & $\mathbf{1 0 1 1}(\mathbf{1 0 0})$ \\
$\mathbf{2 0 1 4}$ & $598(46,79)$ & $680(53,21)$ & $\mathbf{1 2 7 8 ( 1 0 0 )}$ \\
$\mathbf{2 0 1 5}$ & $635(46,01)$ & $745(53,99)$ & $\mathbf{1 3 8 0 ( 1 0 0 )}$ \\
$\mathbf{2 0 1 6}$ & $599(47,65)$ & $658(52,35)$ & $\mathbf{1 2 5 7 ( 1 0 0 )}$ \\
$\mathbf{2 0 1 7}$ & $703(47,18)$ & $787(52,82)$ & $\mathbf{1 4 9 0 ( 1 0 0 )}$ \\
Total & $\mathbf{3 5 4 9 ( 4 7 , 4 9 )}$ & $\mathbf{3 9 2 4}(\mathbf{5 2 , 5 1}$ & $\mathbf{7 4 7 3 ( 1 0 0 )}$ \\
\hline
\end{tabular}

There have been recent reports on resurgence of mumps infections amongst adolescents and young adults in overcrowded and semi-closed settings such as communes, colleges and camps in developed countries $[8-10,14,25]$. In the United States (US), military recruits, a sub-population that has previously been associated with mumps outbreaks, were found not to be involved in the resurgence of mumps infections reported between 1998 and 2007 [8]. This was associated with the decision in 1991, to introduce the MMR vaccine amongst recruits irrespective of previous vaccination status. Although this finding could strengthen a case for booster doses in older age groups, particularly those at high risk such as college students, antibody titres have been found not to be durable, with titres returning to pre-MMR3 dose levels 1 year after vaccination in individuals between 18 and 24 years in a non-outbreak setting [9]. A booster dose of the mumps vaccination is currently recommended only in the setting of an outbreak $[9,10,26-28]$. Although the level of protective antibodies and correlates of protection against mumps infection are not well-defined, suggested causes of the resurgence of infections have included waning immunity over time due to a lack of a durable $\mathrm{T}$-cell mediated response, as well as antigenic differences between vaccine and circulating mumps strains, [1, 4, 7-10, 26-31]. As such, the mismatch between vaccine and circulating mumps strains has also prompted the consideration of a polyvalent vaccine $[1,32]$.

In our study, most of the samples submitted for mumps testing were CSF and blood specimens. One study conducted in Gauteng Province in South Africa used CSF samples from patients who had clinical 


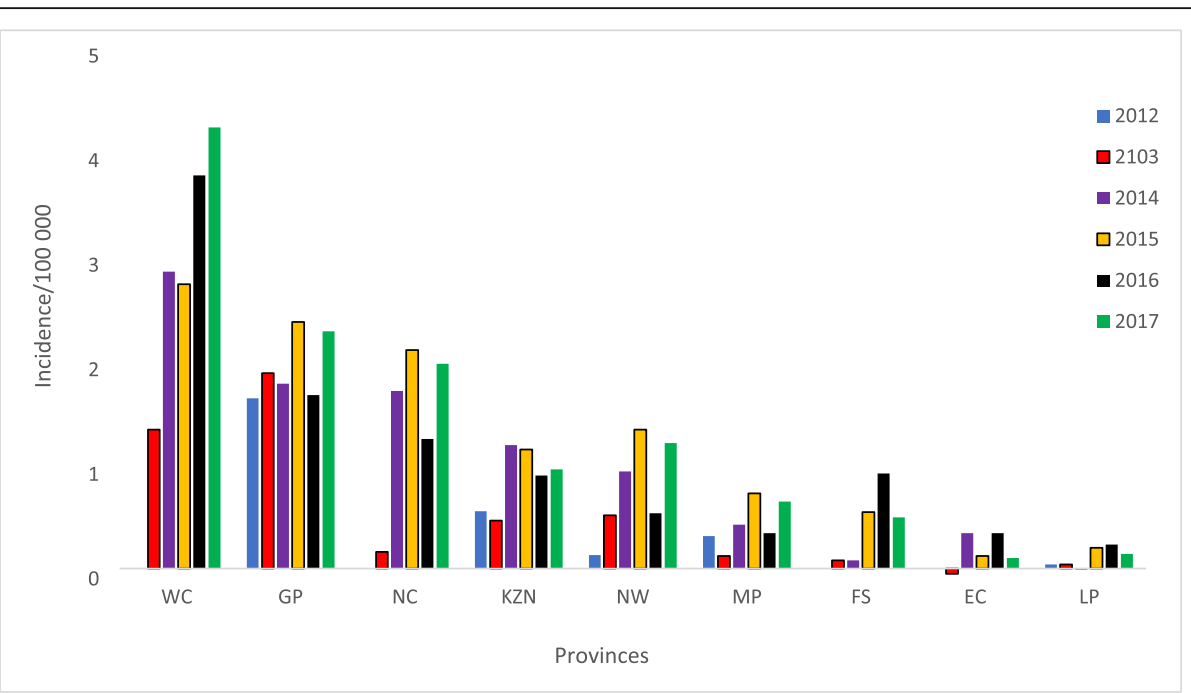

Fig. 3 Incidence per 100,000 population of laboratory-confirmed mumps infections in the public and private sectors by province, 2012-2017

presentation of central nervous system disease (meningitis, encephalitis or other febrile illness with focal neurological signs) to determine the presence of mumps and to characterise the strains, if found [16]. The study found a low frequency of mumps-associated CNS disease $[3 / 260(1.2 \%)]$, and phylogenetic analysis of one detected strain showed that it was a Jeryl-Lynn or RIT4385 vaccine-like strain. A suggestion made by the authors was the establishing of a mumps surveillance programme in the country, which would also provide valuable mumps epidemiological data. At the time of submitting this paper, there was no established surveillance program for mumps in South Africa.
Our finding of a male predominance with regards to infections is similar to what has been reported in other studies $[14,33]$. This has been associated with immunological differences between males and females, where females have been shown to have a stronger T-helper1 cell (Th1) immune response, as well as having persistent and higher antibody levels compared to males [31, 34]. Orchitis has been reported to be the most common complication of mumps infection, and this may also explain the higher proportion of males in this study [6]. Males have also been found to have an increased risk of complications that occur less commonly following mumps infections such as mumps-associated meningitis and encephalitis $[6,34]$.

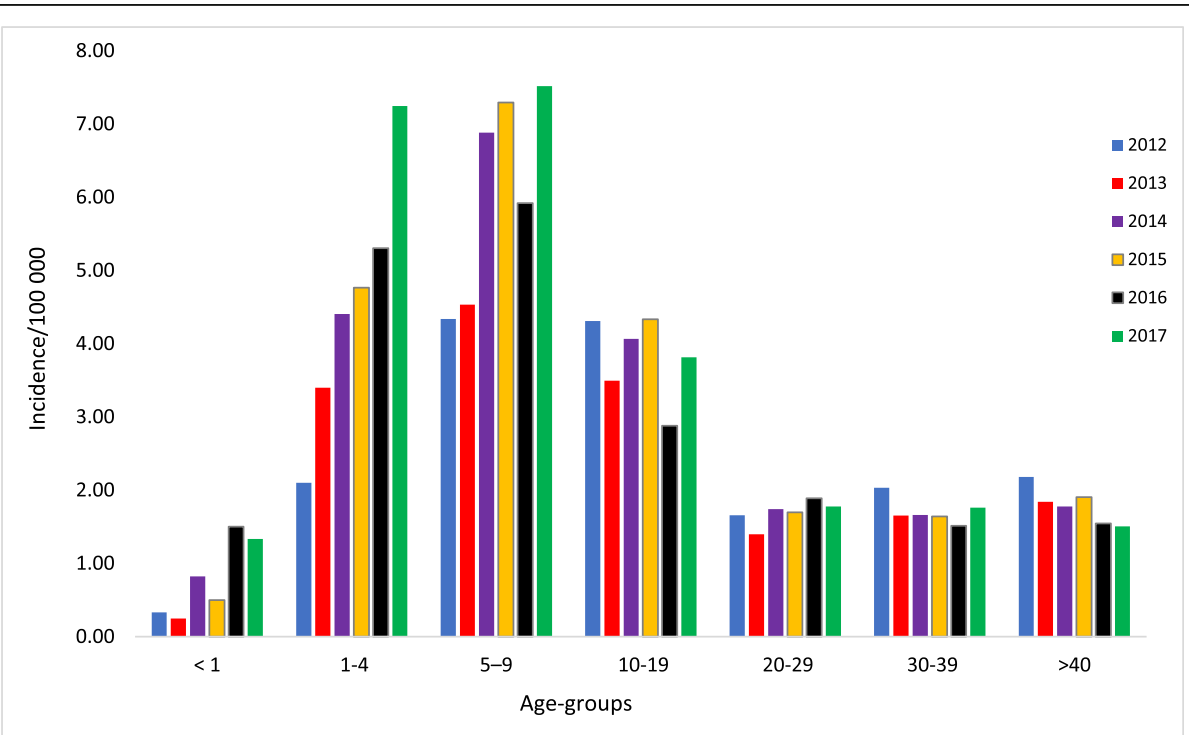

Fig. 4 Incidence per 100,000 population of laboratory-confirmed mumps infections in the public and private sectors by age-group, 2012-2017 


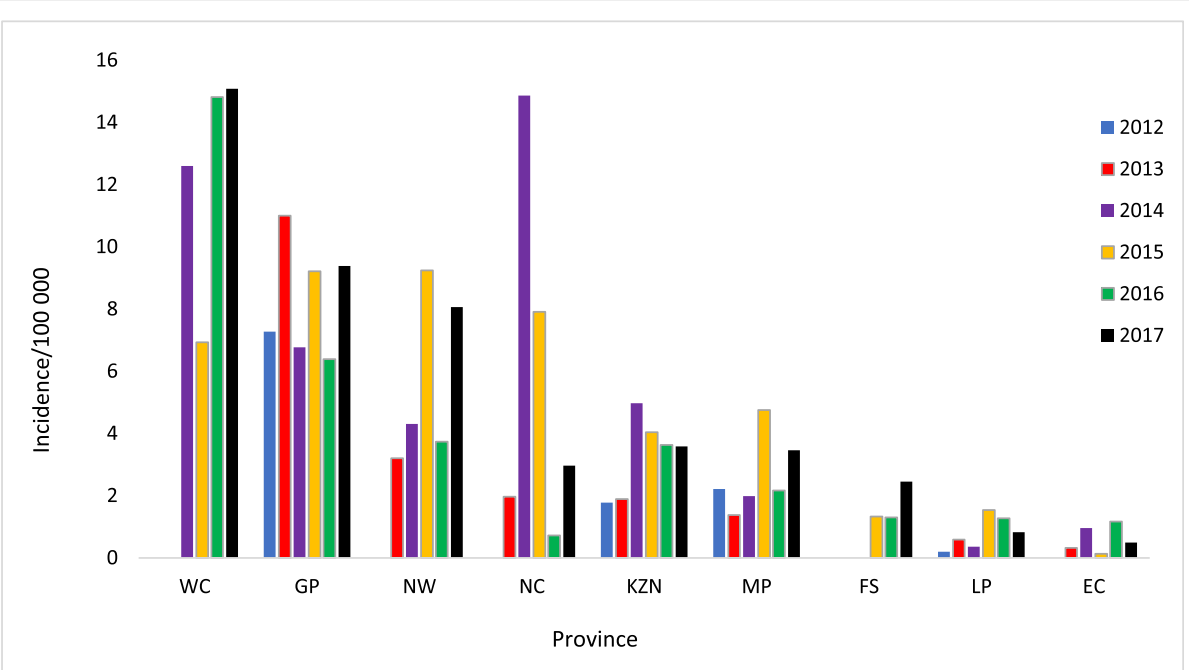

Fig. 5 Incidence per 100,000 of laboratory-confirmed acute infections recorded in the public and private sectors by province, 1-4 year age-group, 2012-2017

The seasonal pattern of mumps infections differs by country, with this difference attributed to environmental, host and viral factors [35]. In our study, we found that the infections peaked in June and November. These months represent the beginning of winter and spring respectively in our setting [36]. A peak in infections in spring and winter has been reported in Jordan [35].

Although Western Cape was seemingly the most affected province with the highest average yearly incidence, the second highest number of recorded samples was from this province (second to Gauteng). Therefore, this province may have been over-represented in the analysis. The geographic distribution of the infections may also be due to the differential availability of laboratory services in the different provinces in the country.

Formulating recommendations for introducing a $\mathrm{MuCV}$, one of the underutilized vaccines in the African region, in South Africa's public health sector (through the EPI), is beyond the scope of this paper, and our study results are also not sufficient to inform such a policy [15]. As previously mentioned, before a MuCV can be introduced in a country, the baseline coverage of the measles-containing vaccine $(\mathrm{MCV})$ should be $>80 \%$. Based on the coverage data for the first and second

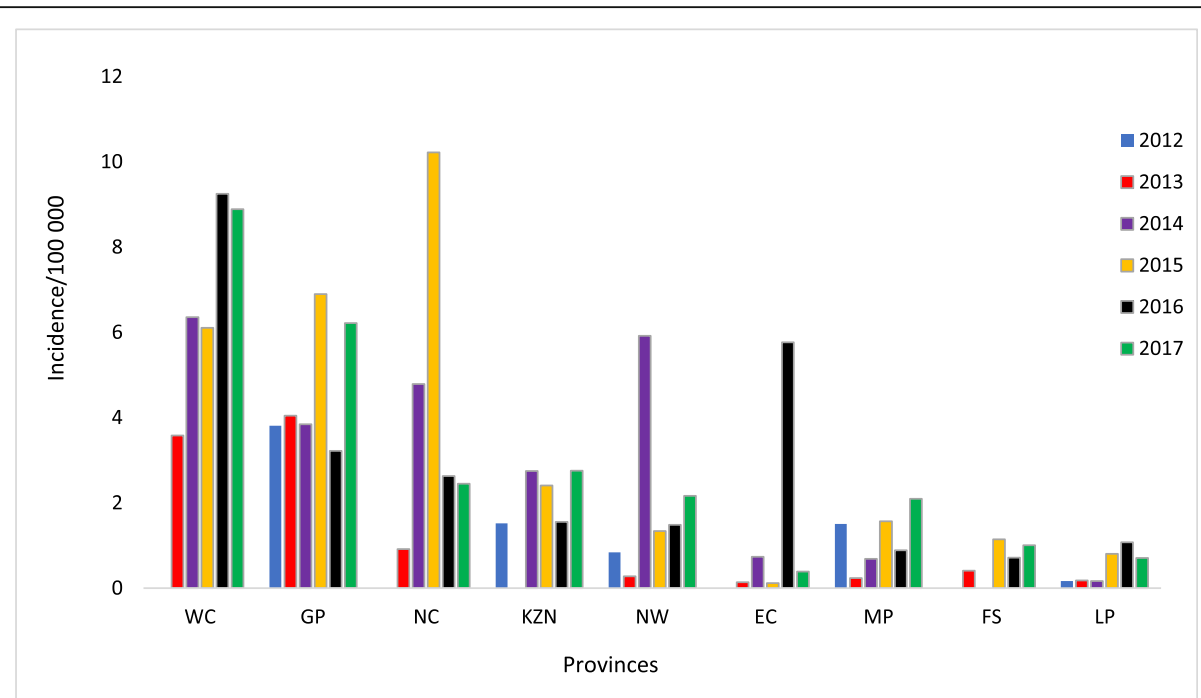

Fig. 6 Incidence per 100,000 of laboratory-confirmed acute infections recorded in the public and private sectors by province, 5-9year age-group, 2012-2017 


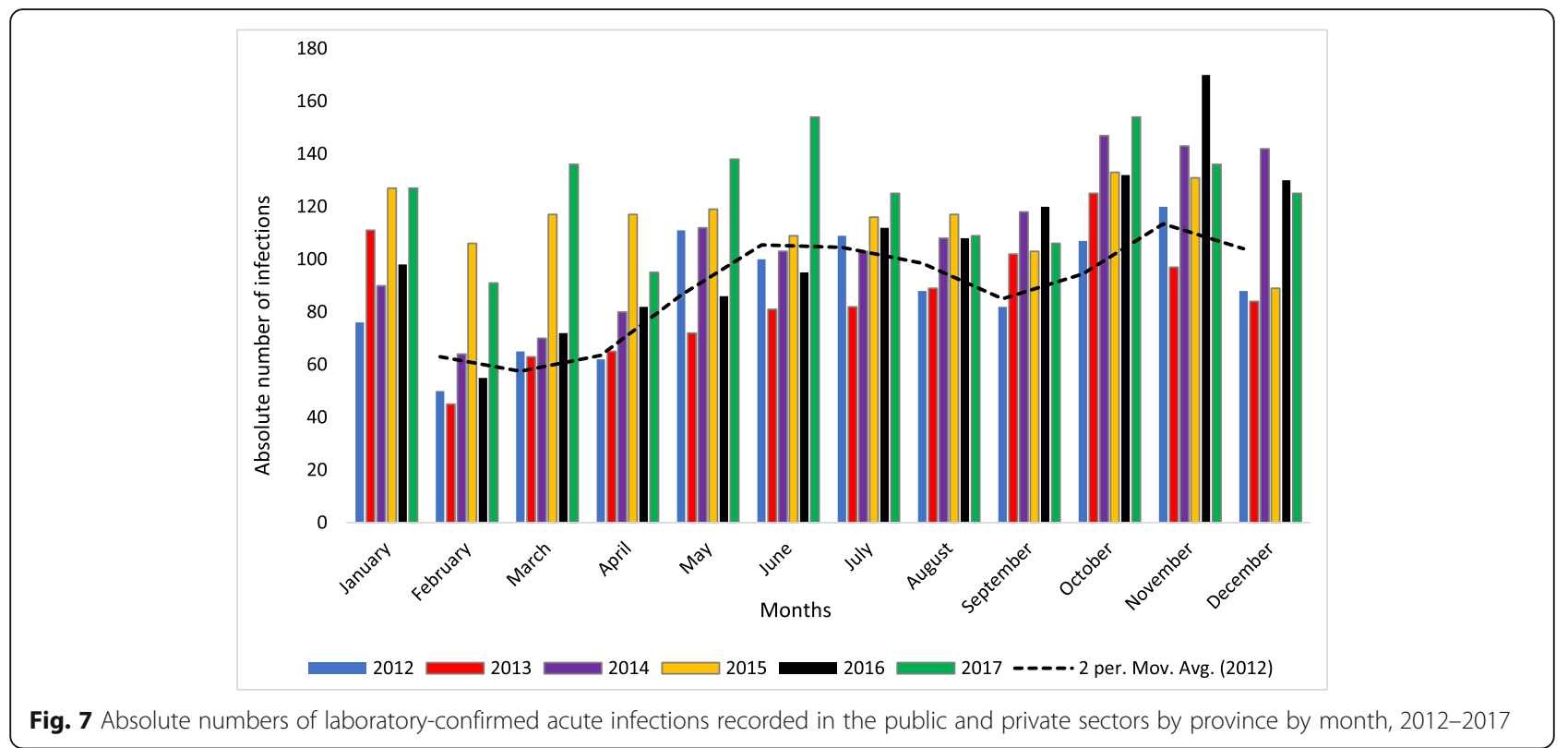

doses of MCV (MCV1 and MCV2 respectively) in South Africa, the MCV1 coverage ranged from $68 \%$ in 2007 to $70 \%$ in 2018 and was $>80 \%$ only during the 2014-2016 period ( $84 \%$ in 2014, 86\% in 2015 and $85 \%$ in 2016) [37]. The MCV2 vaccine coverage estimates (also from 2007 to 2018) showed a drastic decline, with estimates ranging from $49 \%$ in 2007 to $63 \%$ in 2016 . Of note is that these quoted proportions are WHO and UNICEF estimates, and differ from the country's official national and administrative estimates, all of which were $>80 \%$ for the MCV1 and between 70 and 95\% for MCV2 between the 2007-2018 period. Further efforts in increasing the $\mathrm{MCV}$ uptake may therefore be required to meet the recommended baseline MCV vaccine coverage before considering the introduction of a MuCV $[12,38,39]$. Another important consideration regarding the introduction of a MuCV in South Africa's public sector is the vaccine's schedule compared to that of measles. The first dose of MuCV should be given between 12 and 18 months, and the second dose at the age of school entry (around 6 years of age), whereas, at the time that this paper was written, MCV was being given at 6 (first dose) and 12 months (second dose) according to the EPI schedule [13, 17]. Subsequent to the introduction of the $\mathrm{MuCV}$, determining the effectiveness of the vaccine would be necessary. However, this could be challenged by the lack of knowledge regarding correlates of protection against mumps infection [26].

The main strength of our study is that we analysed data from both the public and private health sectors. However, our study had several limitations. Firstly, missing data could not be accounted for and information on risk factors was not available since the secondary data that was analysed did not include information about clinical and medical history. Secondly, 50\% of mumps infections present non-specifically or with respiratory symptoms, while $20-40 \%$ of infections are reportedly asymptomatic or have mild symptoms $[1,27,40]$. These cases may not present at health facilities and would therefore not have been accounted for in the data that

Table 3 Proportion of samples submitted for mumps testing that showed previous exposure in the public and private health sectors, 2012-2017

\begin{tabular}{lllllllllll}
\hline Year & GP n (\%) & KZN n (\%) & MP n (\%) & NW n (\%) & WC n (\%) & LP n (\%) & FS n (\%) & EC n (\%) & NC n (\%) & Totals n (\%) \\
\hline $\mathbf{2 0 1 2}$ & $618(19)$ & $201(20)$ & $30(15)$ & $15(12)$ & $2(2)$ & $13(13)$ & 0 & 0 & 0 & $\mathbf{8 7 9 ( 1 0 0 )}$ \\
$\mathbf{2 0 1 3}$ & $511(15)$ & $186(18)$ & $40(20)$ & $12(10)$ & $5(5)$ & $31(32)$ & 0 & 0 & $6(27)$ & $\mathbf{7 9 1 ( 1 0 0 )}$ \\
$\mathbf{2 0 1 4}$ & $521(16)$ & $196(19)$ & $32(16)$ & $16(13)$ & $1(1)$ & $15(15)$ & $5(20)$ & $6(26)$ & $3(14)$ & $\mathbf{7 9 5 ( 1 0 0 )}$ \\
$\mathbf{2 0 1 5}$ & $545(16)$ & $158(15)$ & $23(11)$ & $31(25)$ & $12(12)$ & $12(12)$ & $4(16)$ & $6(26)$ & $10(45)$ & $\mathbf{7 9 5 ( 1 0 0 )}$ \\
$\mathbf{2 0 1 6}$ & $519(16)$ & $138(13)$ & $39(19)$ & $19(15)$ & $41(41)$ & $15(15)$ & $11(44)$ & $6(26)$ & $3(14)$ & $\mathbf{8 0 1 ( 1 0 0 )}$ \\
$\mathbf{2 0 1 7}$ & $601(18)$ & $145(14)$ & $39(19)$ & $33(26)$ & $38(38)$ & $12(12)$ & $5(20)$ & $5(22)$ & 0 & $\mathbf{7 9 1 ( 1 0 0 )}$ \\
Total & $\mathbf{3 3 1 5 ( 1 0 0 )}$ & $\mathbf{1 0 2 4 ( 1 0 0 )}$ & $\mathbf{2 0 3 ( 1 0 0 )}$ & $\mathbf{1 2 6 ( 1 0 0 )}$ & $\mathbf{9 9 ( 1 0 0 )}$ & $\mathbf{9 8 ( 1 0 0 )}$ & $\mathbf{2 5 ( 1 0 0 )}$ & $\mathbf{2 3 ( 1 0 0 )}$ & $\mathbf{2 2 ( 1 0 0 )}$ & $\mathbf{4 9 3 5 ( 1 0 0 )}$
\end{tabular}

EC Eastern Cape; FS Free State; GP Gauteng; KZN KwaZulu Natal; LP Limpopo; MP Mpumalanga; NW North West; NC Northern Cape; WC Western Cape 
we reviewed. Also, data of cases of acute infection where the diagnosis was made clinically without laboratory confirmation would also not be included in our study. Since mumps was not a notifiable disease in South Africa at the time that this paper was written, case-based data that could have supplemented the laboratory-based data were also not available. The above-mentioned limitations may account for the small numbers of mumps test requests, particularly from the public health sector, where mumps infections are likely to be diagnosed clinically rather than by laboratory testing, due to consideration for resources. Thirdly, we were not able to comment on mumps-related complications in our setting because information on clinical presentation or medical history was not included in the analysed data. Fourthly, differential availability of laboratory services across the provinces may also have had an impact on the completeness of the analysed data. The estimates of acute infections presented may be an underestimation of the true burden of mumps disease and may explain why the cumulative incidence found in our study was lower than the cumulative incidence of $\geq 100$ cases/100000 that has been reported in the pre-vaccine era in other settings.

\section{Conclusion}

Our results showed that, in South Africa, mumps infections mostly affected children below 10 years of age, peaked during winter and spring and predominantly affected males. Fewer tests were performed in the public compared to the private sector, which may have contributed to under-reporting of infections. Since our study results were only based on laboratory test results, conducting further studies that include analysis of clinical data may provide further insight into disease burden in the country.

\section{Abbreviations \\ CNS: Central Nervous System; EC: Eastern Cape Province; EPI: Extended Immunization Programme; FS: Free State Province; GP: Gauteng Province; IgG: Immunoglobulin G; IgM: Immunoglobulin M; KZN: KwaZulu Natal Province; LP: Limpopo Province; MMR: Measles-mumps-rubella; MP: Mpumalanga Province; MuCV: mumps-containing vaccine; NA: nucleic acid; NC: Northern Cape Province; NHLS: National Health Laboratory Service; NPA: Nasopharyngeal Aspirate; NW: North West Province; US: United States of America; WC: Western Cape Province; WHO: World Health Organization}

\section{Acknowledgements}

We would like to acknowledge the following individuals and their respective institutions for providing and allowing use of the anonymous and unlinked data: the National Health Laboratory Service' Corporate Data Warehouse, Dr. Terry Marshall (Ampath Laboratories), Prof. Eftyxia Vardas \& Ms. Jochebeth Naidoo (Lancet Laboratories), Dr. Inez Rossouw \& Ms. Joan Grobler (Drs Dietrich, Voigt, Mia \& Partners ("PathCare")), as well as Dr. Louis Marcus \& Ms. Louise Scholtz (PathCare/Nermaak \& Partners). We would also like to acknowledge Mrs. Dorothy Southern and Dr. Inez Rossouw who assisted in the manuscript review process.

\section{Authors' contributions}

MLS, VNM and LK are all authors that contributed to the conception of the study. MLS requested and acquired raw data from the NHLS data repository as well as private laboratories. MLS, VNM and LK contributed towards analysis and interpretation of the data. MLS, VNM, LK as well as Mrs. Dorothy Southern (scientific writing and technical support to the South African Field Epidemiology Training Programme) and Dr. Inez Rossouw (Pathologist, PathCare) reviewed the manuscript. All authors read and approved the final manuscript.

\section{Funding}

No funding to declare.

\section{Availability of data and materials}

The data used in the analysis are not publicly available. Public sector data were provided and approved for use by the data repository of the National Health Laboratory Service. Private sector data were provided and approved for use by the focal person (pathologists listed in the acknowledgement section) from the respective private sector laboratories [Dr Terry Marshall (Ampath Laboratories), Prof. Eftyxia Vardas (Lancet Laboratories), Dr. Inez Rossouw PathCare as well as Dr. Louis Marcus PathCare/Vermaak \& Partners]. The datasets used and analysed during this current study are available from the corresponding author on reasonable request.

Ethics approval and consent to participate

Ethics approval was obtained from the Faculty of Health Sciences Research Ethics Committee of the University of Pretoria (ref. 539/2017). Institutional clearances were also obtained from the NHLS Academic Affairs, Research and Quality Assurance (for the public health sector data) as well as the relevant ethics committees of the respective private laboratories (for private health sector data).

\section{Consent for publication}

Not applicable.

\section{Competing interests}

The authors declare that they have no competing interests.

\section{Author details}

${ }^{1}$ South African Field Epidemiology Training Programme, National Institute for Communicable Diseases, Division of the National Health Laboratory Service, Johannesburg, South Africa. ${ }^{2}$ Division of Public Health Surveillance and Response, National Institute for Communicable Diseases, Division of the National Health Laboratory Service, Johannesburg, South Africa. ${ }^{3}$ School of Health Systems and Public Health, University of Pretoria, Pretoria, South Africa. ${ }^{4}$ Centre for Vaccines and Immunology, National Institute for Communicable Diseases, a division of the National Health Laboratory Service, Johannesburg, South Africa. ${ }^{5}$ Department of Global Health, Faculty of Medicine and Health Sciences, Stellenbosch University, Stellenbosch, South Africa.

Received: 1 March 2020 Accepted: 3 May 2020

Published online: 12 May 2020

\section{References}

1. Principi N, Esposito S. Mumps outbreaks: a problem in need of solutions. J Inf Secur. 2018;76(6):503-6.

2. World Health Organization-Europe-UNICEF [Online]. Global and regional immunization profile. Last updated 10 Dec 2019. Accessed 19 Apr 2020. Available: https:/www.who.int/immunization/monitoring_surveillance/data/ gs_gloprofile.pdf?ua=1.

3. World Health Organization [Online]. Immunization coverage. Mumps. Last updated 6 Dec 2019. Accessed 10 Apr 2018. Available: https://www.who.int/ en/news-room/fact-sheets/detail/immunization-coverage.

4. Vygen S, Fischer A, Meurice L, Mounchetrou NI, Gregoris M, Ndiaye B, et al. Waning immunity against mumps in vaccinated young adults, France 2013. Euro Surveill. 2016;21(10):30156.

5. Gee S, O'Flanagan D, Fitzgerald M, Cotter S. Mumps in Ireland, 2004-2008. Euro Surveill. 2008;13(18):18857. 
6. Yung CF, Andrews N, Bukasa A, Brown KE, Ramsay M. Mumps complications and effects of mumps vaccination, England and Wales, 2002-2006. Emerg Infect Dis. 2011;17(4):661-7.

7. Dayan GH, Quinlisk MP, Parker AA, Barskey AE, Harris ML, Schwartz JM. Recent resurgence of mumps in the United States. N Engl J Med. 2008;358: 1580-9.

8. Barskey AE, Glasser JW, LeBaron CW. Mumps resurgences in the United States: a historical perspective on unexpected elements. Vaccine. 2009; 27(44):6186-95.

9. Fiebelkorn AP, Coleman LA, Belongia EA, Freeman SK, York D, Bi D, et al. Mumps antibody response in young adults after a third dose of MeaslesMumps-Rubella vaccine. Open Forum Infect Dis. 2014;1(3):ofu094.

10. Beleni A, Borgmann S. Mumps in the vaccination age: global epidemiology and the situation in Germany. Int J Environ Res Public Health. 2018;15:1618.

11. National Institute for Communicable Diseases. Notifiable Medical Conditions [Online]. Accessed 20 Apr 2020. Available: https://j9z5g3w2.stackpathcdn. com/wp-content/uploads/2018/10/Notifiable-Medical-Condition_ZfoldBleed20-July2018.pdf.

12. World Health Organization. WHO vaccine-preventable diseases: monitoring system. 2019 global summary. [Online]. Last updated 10 Dec 2019 Accessed 08 Apr 2020. Available: https://apps.who.int/immunization_ monitoring/globalsummary.

13. World Health Organization. Weekly Epidemiological Record. Mumps virus vaccines; WHO position paper. [Online]. Last updated 16 Feb 2007. Accessed 09 Apr 2020. Available: https://www.who.int/wer/2007/wer8207. pdf?ua=1.

14. Hassan J, Dean J, Moss E, Carr MJ, Hall WW, Connell J. Seroepidemiology of the recent mumps virus outbreaks in Ireland. J Clin Virol. 2012 Apr;53(4): 320-4.

15. Sambala EZ, Wiyeh A, Ngcobo N, Machingaidze S, Wiysonge CS. New vaccine introductions in Africa before and during the decade of vaccines are we making progress? Vaccine. 2019;37(25):3290-5.

16. Brauer M, Wolfaardt M, Webber LM, Taylor MB. Molecular detection and characterisation of mumps virus in cerebrospinal fluid in a Gauteng laboratory. South African J Infect Dis. 2016;31(1):29-31.

17. Motaze NV, Suchard M, Cohen C, Baker L, Blumberg L, ed. Vaccine information for parents and caregivers. Johannesburg: Ideas Wise and Wonderful for National Institute for Communicable Diseases, 2016. [cited 2018 April 20]. Available at: http://www.nicd.ac.za/assets/files/NICD_ Vaccine_Booklet_D132_FINAL.pdf.

18. National Health Laboratory Service. Who we are. [Online]. Accessed 20 April 2018. Available from: hhtp://www.nhls.ac.za/?page=who are we $\& i d=17$.

19. Statistics South Africa. Statistics release P0302. Mid-year population estimates Vol. P0302. 2011. [Online]. Accessed 5 May 2018. Available: http:// www.statssa.gov.za/publications/P0302/P03022011.pdf.

20. Statistics South Africa. Statistical release P0302. Mid-year population estimates Vol. P0302. 2013. [Online]. Accessed 5 May 2018. Available: https:// www.statssa.gov.za/publications/P0302/P03022013.pdf.

21. Statistics South Africa. Statistical release P0302. Mid-year population estimates Vol. P0302. 2014. [Online]. Accessed 5 May 2018. Available: https:// www.statssa.gov.za/publications/P0302/P03022014.pdf.

22. Statistics South Africa. Statistical release P0302. Mid-year population estimates Vol. P0302. 2015. [Online]. Accessed 5 May 2018. Available: https:// www.statssa.gov.za/publications/P0302/P03022015.pdf.

23. Statistics South Africa. Statistical release P0302. Mid-year population estimates Vol. P0302. 2016. [Online]. Accessed 5 May 2018. Available: https:// www.statssa.gov.za/publications/P0302/P03022016.pdf.

24. Statistics South Africa. Statistical release P0302. Mid-year population estimates Vol. P0302. 2017. [Online]. Accessed 5 May 2018. Available: http:// www.statssa.gov.za/publications/P0302/P03022017.pdf.

25. Su SB, Chang HL, Chen AK. Current status of mumps virus infection: epidemiology, pathogenesis, and vaccine. Int J Environ Res Public Health. 2020;17(5):1686.

26. Latner DR, Hickman CJ. Remembing Mumps. PLoS Pathog. 2015;11(5): e1004791.

27. Lam E, Rosen JB, Zucker JR. Mumps: an update on outbreaks, vaccine efficacy, and genomic diversity. Clin Microbiol Rev. 2020;33:e00151-19.

28. Bankamp B, Hickman C, Icenogle JP, Rota PA. Successes and challenges for preventing measles, mumps and rubella by vaccination. Curr Opin Virol. 2019;34:110-6

29. López-Perea N, Masa-Calles J. Torres de Mier M de V, Fernández-García a Echevarría JE, De Ory F, et al. shift within age-groups of mumps cumulative incidence, hospitalizations and severe complications in a highly vaccinated population. Spain, 1998-2014. Vaccine. 2017:35(34):4339-45.

30. LeBaron CW, Forghani B, Beck C, Brown C, Bi D, Cossen C. Persistence of mumps antibodies after 2 doses of measles-mumps-rubella vaccine. J Infect Dis. 2009;199:552-60.

31. Kenny L, O'Kelly E, Connell J, De Gascun C, Hassan J. Mumps outbreaks in a highly vaccinated population: investigation of a neutralization titre against the current circulating wildtype genotype G5 mumps virus. J Clin Virol. 2016;74:8-12.

32. May M, Rieder CA, Rowe RJ. Emergent lineages of mumps virus suggest the need for a polyvalent vaccine. J Infect Dis. 2018:66:1-4.

33. Sane J, Gouma S, Koopmans M, de Melker H, Swaan C, van Binnendijk R, et al. Epidemic of mumps among vaccinated persons, the Netherlands, 2009-2012. Emerg Infect Dis. 2014;20(4):643-8.

34. Muenchhoff M, Goulder PJ. Sex differences in pediatric infectious diseases. J Infect Dis. 2014;209(Suppl 3):S120-6.

35. Ho YC, Su BH, Su HJ, Chang HL, Lin CY, Chen H, et al. The association between the cumulative incidence of mumps and meteorological parameters in Taiwan. Hum Vaccin Immunother. 2015;11(6):1406-12.

36. South African Weather Service. Weather questions. [Online]. Accessed 15 Apr 2018. Available: https://www.weathersa.co.za/home/weatherques.

37. World Health Organization. WHO and UNICEF estimates of immunization coverage: 2018 revision. [online]. Last updated 2 Jul 2019. Accessed 10 Apr 2020. Available: https://www.who.int/immunization/monitoring_ surveillance/data/zaf.pdf.

38. Cameron NA. When, and how, should we introduce a combination measles-mumps-rubella (MMR) vaccine into the national childhood expanded immunization programme in South Africa? Vaccine. 2012;30(suppl 3):C58-60

39. Schoub BD, Harris BN, McAnerney J, Blumberg L. Rubella in South Africa: an impending Greek tragedy? SAMJ. 2009;99(7):515-9.

40. Qu Q, Fang C, Zhang L, Jia W, Weng J, Li Y. A mumps model with seasonality in China. Infect Dis Model. 2017:2(1):1-11.

\section{Publisher's Note}

Springer Nature remains neutral with regard to jurisdictional claims in published maps and institutional affiliations.
Ready to submit your research? Choose BMC and benefit from:

- fast, convenient online submission

- thorough peer review by experienced researchers in your field

- rapid publication on acceptance

- support for research data, including large and complex data types

- gold Open Access which fosters wider collaboration and increased citations

- maximum visibility for your research: over $100 \mathrm{M}$ website views per year

At $\mathrm{BMC}$, research is always in progress.

Learn more biomedcentral.com/submissions 